\title{
Effects of Process Parameters on the Size of Nanostructure Magnesium Oxide Synthesized by a Surfactant and Ligand Assisted Wet Chemical Method
}

\author{
Amirmasoud Sabourimanesh ${ }^{*}$, Alimorad Rashidi ${ }^{2}$, Katayoun Marjani', \\ Parizad Motamedara1, Yousef Valizadeh ${ }^{1}$ \\ ${ }^{1}$ Department of Chemistry, University of Kharazmi, Tehran, Iran \\ ${ }^{2}$ Research Institute of Petroleum Industry, Tehran, Iran \\ Email: ${ }^{*}$ asadollahsamodi@yahoo.com.sg
}

Received 23 January 2015; accepted 30 May 2015; published 2 June 2015

Copyright (C) 2015 by authors and Scientific Research Publishing Inc.

This work is licensed under the Creative Commons Attribution International License (CC BY).

http://creativecommons.org/licenses/by/4.0/

c) (i) Open Access

\begin{abstract}
A surfactant and ligand assisted wet chemical method was employed for the preparation of nanostructure magnesium oxide with a high specific area and sphere-like nanoparticles. The influence of surfactants and ligands on the crystallite size and morphology of MgO was studied using various parameters. X-ray diffraction (XRD) studies show that the crystallite size varies. Observations with Field Emission Scanning Electron Microscopy (FFSEM) and Transmission Electron Microscopy (TEM) show that the ligands and surfactants strongly affect the size of nanostructure. We synthesized less than $15 \mathrm{~nm}$ using a PVA 72000 surfactant in the presence of EDA and 4-methyl morpholine ligands, 15 - $40 \mathrm{~nm}$ with a PVA 72000 surfactant in the presence of oleic acid, and more than $40 \mathrm{~nm}$ with a PEG 6000 surfactant. The effects of several process parameters, such as surfactant, ligand and solvent, were examined.
\end{abstract}

\section{Keywords}

Magnesium Oxide, Crystal Structure, Nanostructure, FESEM, XRD, Surfaces

\section{Introduction}

Metal oxide nanomaterials exhibit unique physical and chemical properties and have potential applications in "Corresponding author.

How to cite this paper: Sabourimanesh, A., Rashidi, A., Marjani, K., Motamedara, P. and Valizadeh, Y. (2015) Effects of Process Parameters on the Size of Nanostructure Magnesium Oxide Synthesized by a Surfactant and Ligand Assisted Wet Chemical Method. Crystal Structure Theory and Applications, 4, 28-34. http://dx.doi.org/10.4236/csta.2015.42004 
magnetism catalysis, electro optical devices, sensors, and nanodevices [1]-[3]. Magnesium oxide is suitable for insulation applications due to its low heat capacity and high melting point [4]. MgO is used as a fundamental material for chemical pumps [5], and as a substrate material for the epitaxial growth of thin films with desired electronic or magnetic properties [6]. MgO-thin films have been proposed for use as protective coating on phosphor screens [7] and as a substrate for carbon nanotubes growth [8]. Nano-sized MgO can be used for relative adsorbents. They have been used for the decontamination of chemical warfare agents [9], reducing cholorofluoro carbons [10]. Wet chemical is a method for the synthesis of nanostructure MgO. Various morphologies nanostructures of MgO, including nanowires, branched nanostructures nanotubes and nanocubes, have been obtained [10]. Over the past few years, synthesis methods have been developed for the preparation of nanocrystalline MgO, including sol-gel [11] [12], hydrothermal [8], laser vaporization [9], chemical gas phase deposition [10], combustion aerosol synthesis [11], and precipitation [13].

In this paper, we have described a simple, economical, and moderately low temperature $\left(500^{\circ} \mathrm{C}\right)$ solution for the preparation of $\mathrm{MgO}$ nanopowder. The decomposition of the $\mathrm{Mg}(\mathrm{OH})_{2}$ intermediate phase in the presence of PVA and PEG surfactants gave highly monodispersed MgO particles, with a crystal size of less than 15, 15 - 40 and more than $40 \mathrm{~nm}$.

\section{Experiment}

Materials: magnesium acetate butahydrate $\mathrm{Mg}\left(\mathrm{CH}_{3} \mathrm{COO}\right)_{2} \cdot 4 \mathrm{H}_{2} \mathrm{O}$, poly ethylene glycol (PEG; MW: 6000), dimethyl solfoxide (DMSO), sodium hydroxide $(\mathrm{NaOH})$, ethanol $\left(\mathrm{C}_{2} \mathrm{H}_{5} \mathrm{OH}\right)$, methanol $\left(\mathrm{CH}_{3} \mathrm{OH}\right)$, citric acid $\left(\mathrm{C}_{6} \mathrm{H}_{8} \mathrm{O}_{7}\right)$, sorbitol $\left(\mathrm{C}_{6} \mathrm{H}_{14} \mathrm{O}_{6}\right)$, 4-methyl morpholine and $\mathrm{EG}\left(\mathrm{C}_{2} \mathrm{H}_{6} \mathrm{O}_{2}\right)$, EDA (di ethylene amine monohydrate), oleic acid $\left(\mathrm{C}_{18} \mathrm{H}_{34} \mathrm{O}_{2}\right)$, and poly vinyl alcohol (PVA; MW: 72000) were purchased from Merck and used without further purification. De-ionized water was used throughout this study.

Synthesis: Nanostructure MgO was produced using a wet chemical method. For synthesis of MgO nanoparticles, $10.723 \mathrm{~g} \mathrm{Mg}\left(\mathrm{CH}_{3} \mathrm{COO}\right)_{2} \cdot 4 \mathrm{H}_{2} \mathrm{O}$ and $50 \mathrm{ml}$ oleic acid were dissolved in $100 \mathrm{ml}$ of $\mathrm{H}_{2} \mathrm{O}$ (de-ionized water) under vigorous stirring conditions at $25^{\circ} \mathrm{C}$. Then while stirring, a mixture of $\mathrm{NaOH} 4 \mathrm{M}$ and 2 g PEG 6000 was added dropwise to the solution at room temperature until a $\mathrm{pH}$ of 10 was reached. After being vigorously stirred, the final white solution was kept at a temperature of $65^{\circ} \mathrm{C}$ for four hours. After precipitation, the solution was stirred for another two hours and then filtered and washed several times with deionized water and alcohol. It was finally dried at $85^{\circ} \mathrm{C}$ in air overnight and calcined in air at $500^{\circ} \mathrm{C}$ for five hours using a muffle furnace.

The experiment was carried out again using 2 g PEG 6000 and $50 \mathrm{ml}$ sorbitol ligand in the $100 \mathrm{ml} \mathrm{CH}_{3} \mathrm{OH}$ solvent, $20 \mathrm{~g}$ citric acid ligand for strong citric acid in the presence $100 \mathrm{ml} \mathrm{H}_{2} \mathrm{O}$ solvent and $2 \mathrm{~g}$ citric acid ligand in the presence $100 \mathrm{ml} \mathrm{H}_{2} \mathrm{O}$ solvent, $2.4 \mathrm{~g}$ tri Phenyl Phosphine ligand in the presence $100 \mathrm{ml}$ EG solvent. The experimental procedure was the same as the above synthesis.

To synthesize a sample with poly vinyl alcohol surfactant, first $2 \mathrm{~g}$ PVA 72000 was dissolved in $100 \mathrm{ml}$ water at $90^{\circ} \mathrm{C}$ under vigorous stirring to form a transparent solution. The experimental procedure was the same as the above synthesis.

The experiment was carried out again using 2 g PVA 72000 and $50 \mathrm{ml}$ sorbitol ligand in the $100 \mathrm{ml}_{2} \mathrm{O}$ solvent, 2 g PVA 72000 and $50 \mathrm{ml}$ EDA ligand in the presence of $100 \mathrm{ml}$ ETOH solvent, 2 g PVA 72000, and 50 $\mathrm{ml}$ 4-methyl morpholine ligand in the presence of $100 \mathrm{ml} \mathrm{H}_{2} \mathrm{O}$ solvent. The experimental procedure was the same as the above synthesis.

Characterization: The morphology and the crystalline structures of the as-grown products were characterized by Field Emission Scanning Electron Microscopy (FESEM, Hitachi S4160 Cold Field Emission, Japan), Transmission Electron Microscopy (TEM, Model EM 900, Company Zeiss) and X-ray diffract meter (XRD, diffractometer using the $\mathrm{Cu} \mathrm{K2} \alpha$ source at $40 \mathrm{kV}$ and $40 \mathrm{~mA}$ ). The infrared spectrum of the $\mathrm{MgO}$ was measured by a Perkin-Elmer spectrum RXI FT-IR spectrometer. The surface area was measured by being calcined in air at $500^{\circ} \mathrm{C}$ for five hours (BET, Belsorp mini II, Japan).

\section{Results and Discussion}

Figure 1 represents the FESEM images of $\mathrm{MgO}$ calcined at $500^{\circ} \mathrm{C}$ and $\mathrm{Mg}(\mathrm{OH})_{2}$ in the PEG 6000 and oleic acid ligand, the PVA 72000 and oleic acid ligand, and the PVA 72000 and EDA ligand, respectively. From the FESEM observation, the $\mathrm{Mg}(\mathrm{OH})_{2}$ precursor contains surfactant PEG 6000 with plate-like morphology, and the 


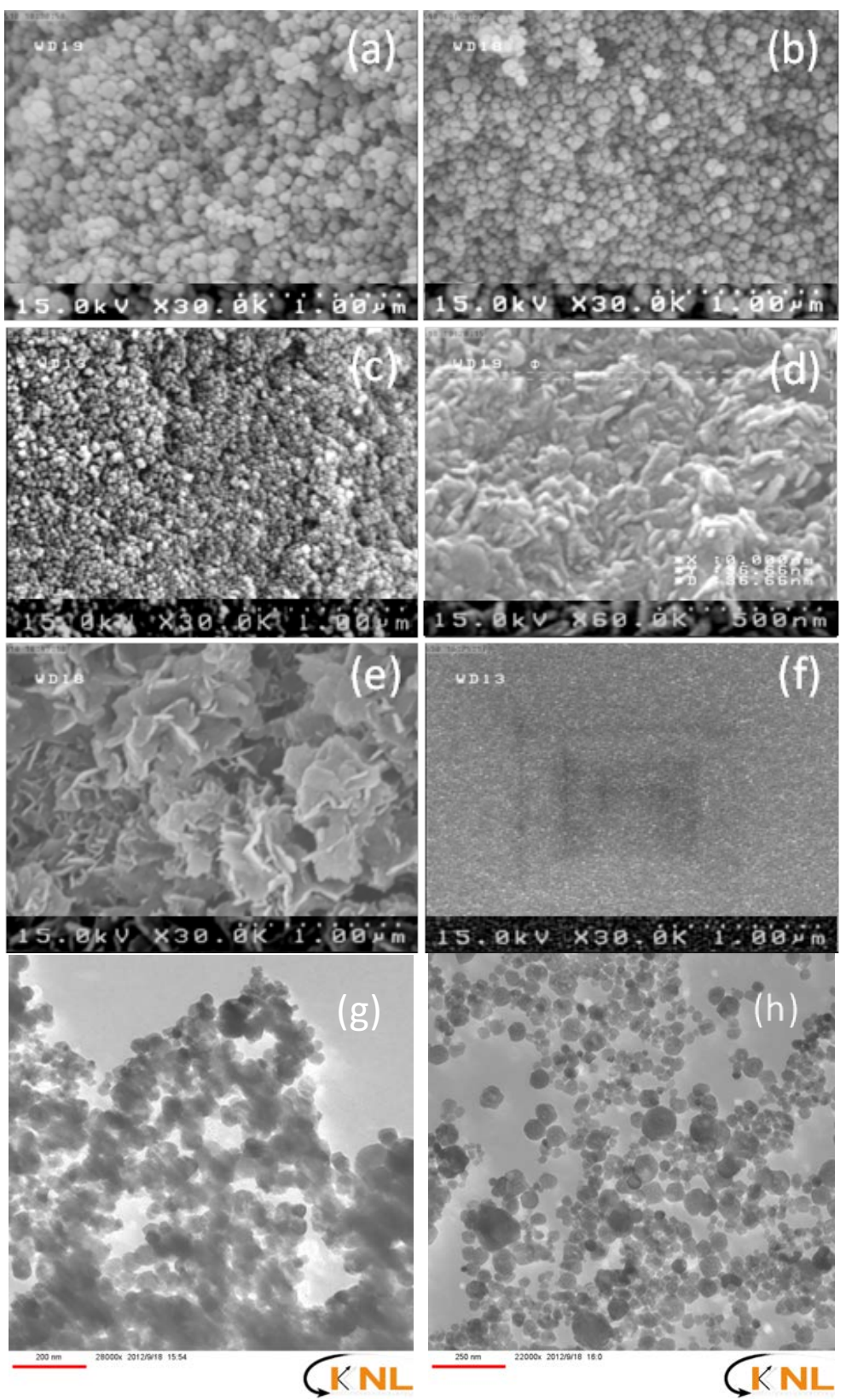

Figure 1. The FESEM images of MgO in: (a)-(c) PEG 6000 and oleic acid, PVA 72000 and oleic acid, PVA 72000 and EDA at $500^{\circ} \mathrm{C}$. The FE-SEM images of $\mathrm{Mg}(\mathrm{OH})_{2}$ in: (d)-(f) PEG 6000 and oleic acid, PVA 72000 and oleic acid, PVA 72000 and EDA. The TEM images of MgO in citric acid (g), PVA 72000 and EDA (h).

produced MgO shows a different morphology (sphere-like). The $\mathrm{Mg}(\mathrm{OH})_{2}$ precursor contains surfactant PVA 72000 and an oleic acid ligand with a plate-like morphology, and the produced MgO shows a different morphology (sphere-like). However, the $\mathrm{Mg}(\mathrm{OH})_{2}$ precursor contains surfactant PVA 72000 and an EDA ligand with a sphere-like morphology, and the produced MgO also shows the same morphology. The effects of the ligand and surfactant on the size of nanostructure magnesium oxide show that changing the surfactant from PEG to PVA resulted in a decrease in the particle size (from an average of $40 \mathrm{~nm}$ to $12 \mathrm{~nm}$ ). The results showed that adding PVA has a significant effect on the structural properties and increased the specific surface area. These images clearly show homogeneous nanostructures as well as remarkably different conditions. We have observed an agglomeration of particles in all the cases due to prolonged reaction time [14] [15]. The agglomeration effect 
was prominent in aqueous solvent compared to organic solvents [16]. A particle size of $8 \mathrm{~nm}$ was obtained in PVA, diethylene amine and ETOH. According to this report, the surfactant, together with the ligand, played an important role in determining the morphology and size of the products. For systematic transformation, a series of controlled experiments was carried out. First, we regularly changed the reaction surfactant while other reaction limits were kept constant. As can be seen in Figure 1(a) and Figure 1(b), the morphology was not changed but the particle size of the MgO was reduced by changing the surfactant from PEG 6000 to PVA 72000.

The TEM images of $\mathrm{MgO}$ calcined at $500^{\circ} \mathrm{C}$ is shown in Figure 1. As can be seen, both the samples show a nanocrystalline structure with a spherical shape. Figure 1(g) shows the TEM topography of nano-sized MgO with a length of $22 \mathrm{~nm}$ and a breadth of $25 \mathrm{~nm}$. Figure 1 (g) also shows the layered structure of MgO. The spherical shape of nano-sized MgO is shown in Figure 1(h). With a length of $12 \mathrm{~nm}$ and a breadth of $16 \mathrm{~nm}$, the sphere-like particles are presented without any agglomeration.

Several factors, including the surfactant and the ligand, have an impact on the particle size and surface area. The particle size of MgO increased rapidly when the surfactant was changed from PVA 72000 to PEG 6000.

The mechanism of $\mathrm{MgO}$ is usually accepted as follows:

$$
\begin{aligned}
& \mathrm{Mg}\left(\mathrm{CH}_{3} \mathrm{COO}\right)_{2} \cdot 4 \mathrm{H}_{2} \mathrm{O}+2 \mathrm{NaOH} \rightarrow \mathrm{Mg}(\mathrm{OH})_{2}+2 \mathrm{CH}_{3} \mathrm{COONa}+4 \mathrm{H}_{2} \mathrm{O} \\
& \mathrm{Mg}(\mathrm{OH})_{2}+\mathrm{Heat}\left(500^{\circ} \mathrm{C}\right) \rightarrow \mathrm{MgO}+\mathrm{H}_{2} \mathrm{O} \mathrm{NaOH}+\text { heat } \rightarrow \text { No Reaction }
\end{aligned}
$$

There are many separated colloidal $\mathrm{Mg}(\mathrm{OH})_{2}$ clusters in the preformed suspension, some of which can act as the nuclei for MgO growth. The existence of hydroxyl groups limits the growth of MgO nuclei [17] [18].

The investigation into the effects of surfactant and ligand on the morphology and crystal size of the samples, as illustrated in Figure 2(a) and Figure 2(b), show that changing the amount of citric acid ligand from $2 \mathrm{~g}$ to 20 g, when other reaction parameters are kept constant, increases their size. Figure 2(c) and Figure 2(d) show that
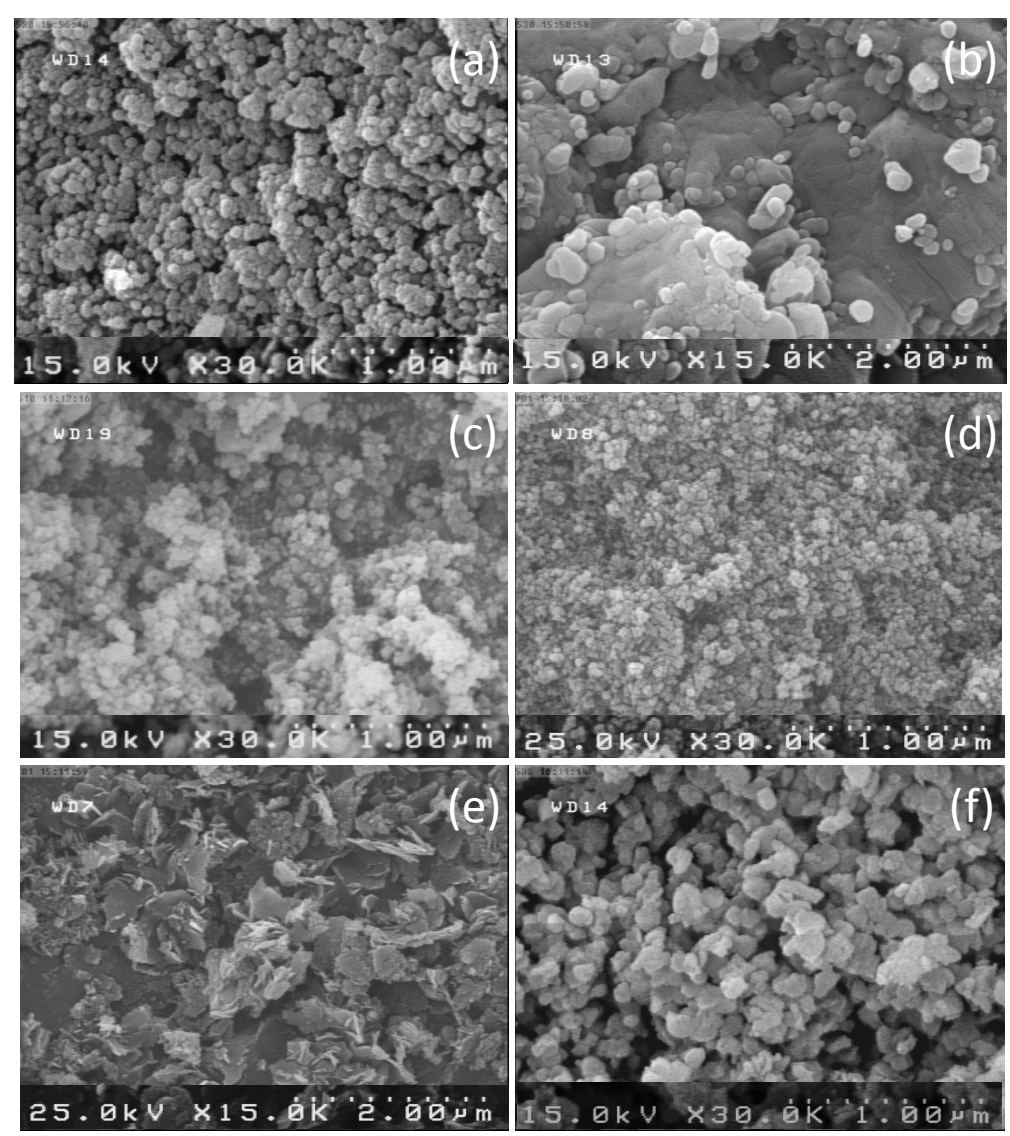

Figure 2. The FE-SEM images of $\mathrm{MgO}$ at $500^{\circ} \mathrm{C}$ : (a) citric acid; (b) strong citric acid; (c) PEG 6000 and sorbitol; (d) PVA 72000 and sorbitol; (e) PVA 72000 and 4-methyl morpholine; (f) EG. 
changing the surfactant from PEG 6000 to PVA 72000, when other reaction parameters are kept consonant, reduces its size. Figure 2(d) and Figure 2(e) also show that changing the ligand from sorbitol to 4-methyl morpholine, when other reaction parameters are kept constant, changes the morphology from nanospherical particle to nanocube particle.

XRD: The crystal structure of the MgO sample (Figure 3) was measured from the X-ray brodline by using the Scherrer equation:

$$
\mathrm{d}=0.089 /(\mathrm{B}(2) \cos )
$$

where $\mathrm{B}(2 \theta)$ is the width of the XRD pattern line at half peak-height (rad), $\lambda$ the wavelength of the X-ray, $\theta$ the angle between the incident and diffracted beams, and $d$ the crystal size of the powder sample (nm) [19] [20]. The $\mathrm{X}$-ray diffracts gram shows two sharp lines. The other crystal planes were suppressed and confirmed the semicrystalline nature of MgO. The appearance of the d crystal plane authenticated the structure of the MgO hexagonal-like structure. In this investigation, our aim was to prove that $\mathrm{MgO}$ synthesized by the one-pot method is nano sized with a layered structure.

$\mathrm{N}_{2}$ adsorption isotherm: The specific surface (SA) of MgO nanoparticles is determined by a BET method. The theoretical size of the particles was also calculated from the following equation:
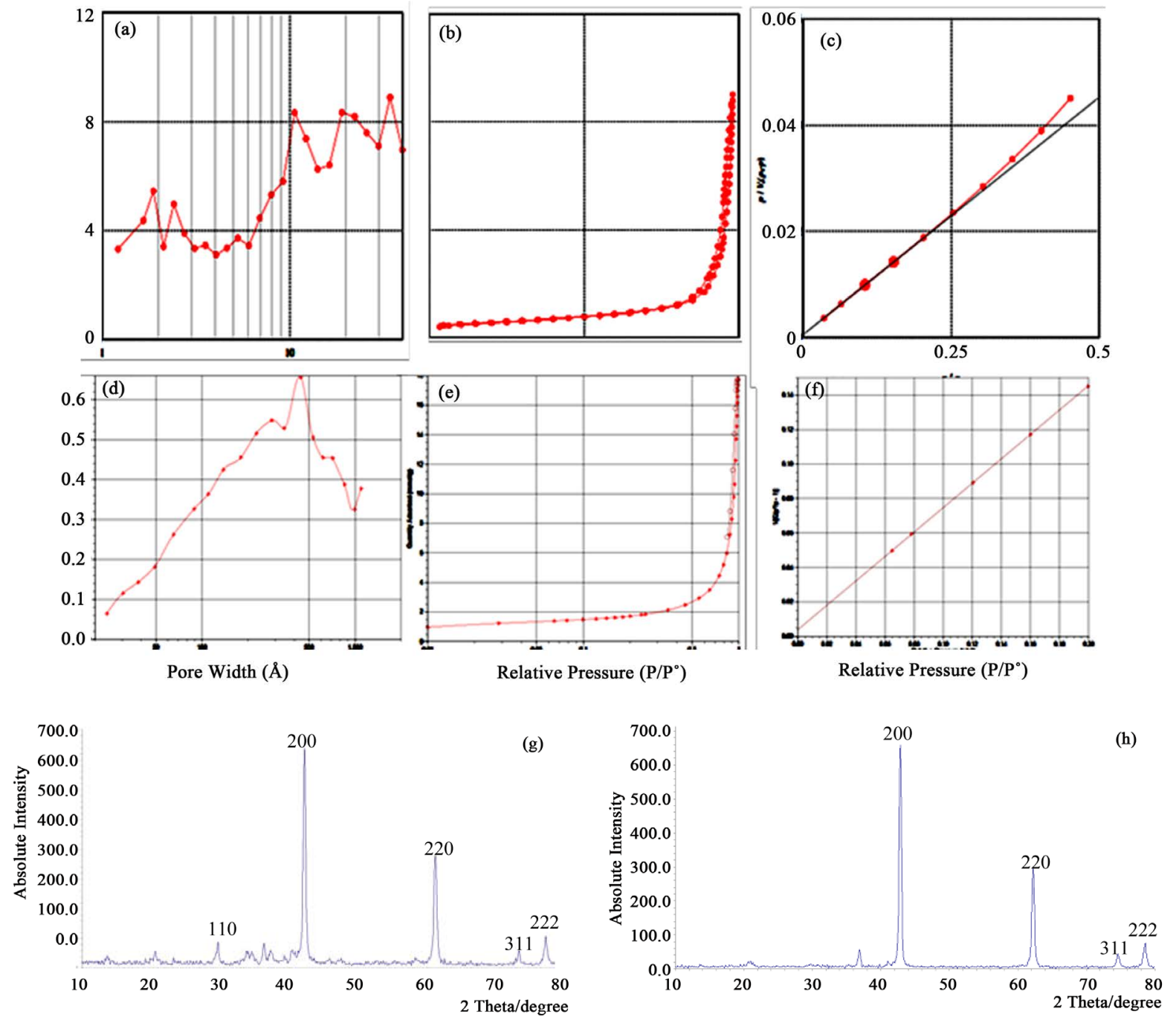

Figure 3. The pore diameter distribution, $\mathrm{N}_{2}$ adsorption and a BET plot ((a), (b), (c)) in the PEG 6000, and ((d), (e), (f)) in the PVA 72000 respectively, (g, h) The wide-angled XRD patterns of (g) MgO in PVA 72000, (h) MgO in citric acid. 


$$
\mathrm{D}_{\mathrm{BET}}=\left(\frac{6000}{\rho^{*} \mathrm{~S}}\right)
$$

where $\mathrm{D}_{\mathrm{BET}}$ is the equivalent of the particle diameter in nanometers, $\rho$ is the density of the material in $\mathrm{g} \cdot \mathrm{cm}^{-3}$ and $\mathrm{S}$ is the specific surface area in $\mathrm{m}^{2} \cdot \mathrm{g}^{-1}$.

Figure 3 shows the distribution curve of pores size, the isotherm of corresponding nitrogen adsorption/desorption, and the BET surface area plot of the produced $\mathrm{MgO}$. The distribution of pores volume with their radius is calculated by the BJH method. The MgO samples show relatively narrow pore size distributions. Their average pore sizes were in the range of 13.66 - $14.57 \mathrm{~nm}$, the average particle sizes fell into the range $34.6-12.22$ $\mathrm{nm}$, the average pore volume fell into the range $(\mathrm{v} \mathrm{p}) 0.29-0.57 \mathrm{~m}^{3} \cdot \mathrm{g}^{-1}$, and the average surface area fell into the range $48.8-136.95 \mathrm{~m}^{2} \cdot \mathrm{g}^{-1}$ for the surfactant PEG 6000 in the presence of a sorbitol ligand and PVA 72000 in the presence of an EDA ligand, respectively. According to the IUPAC classification, the $\mathrm{N}_{2}$ isotherm is an isotherm type III with a large type H3 Hysteresis loop. This type of hysteresis is usually found in solids consisting of aggregates or agglomerates of particles forming slit-shaped pores with no uniform size and/or shape. The nitrogen adsorption method has been used to determine the BET surface area and the pore size distribution of typical MgO powder obtained by decomposing $\mathrm{Mg}(\mathrm{OH})_{2}$ at $500^{\circ} \mathrm{C}$ for three hours. The sample has a Langmuir surface area of about $187.69 \mathrm{~m}^{2} \cdot \mathrm{g}^{-1}$ in PVA 72000 . The average particle size as deduced from the BET specific surface area is $12.22 \mathrm{~nm}$. The value of the BET surface area and pore volume can improve the characteristics of $\mathrm{MgO}$ powder to make it suitable for catalytic activity and adsorption and dissociation of molecules, such as $\mathrm{CH}_{3} \mathrm{OH}, \mathrm{CH}_{4}, \mathrm{NO}_{2}, \mathrm{H}_{2} \mathrm{O}, \mathrm{CO}$ and $\mathrm{CO}_{2}$, toxic waste remediation, etc. [16]-[18].

\section{Conclusions}

In summary, nanodispersed MgO particles with crystal size $<15,15$ - 40 and $>40 \mathrm{~nm}$ have been prepared by a wet chemical method at a low temperature. The results of the experiments show that surfactant and ligand play a key role in the composition of the precursor, which has determinative effects on the size of the obtained MgO nanoparticles.

The wet chemical method has been developed for the preparation of $\mathrm{MgO}$ nano with excellent basic catalytic activity. The preparation method of MgO nanoparticles is versatile and easily scalable, and is based on using cheap and abundant chemicals. The synthesis avoids extreme reaction conditions and high pressure treatment. The XRD results confirmed the hexagonal crystal structure of MgO. The FESEM clearly shows homogeneous nanostructures and remarkably different agglomerate sizes in different ligands and different surfactants, implying that the selection of the ligand and surfactant is a key factor for obtaining a high quality of nano-sized MgO via the wet chemical method.

\section{Acknowledgements}

This work was sponsored by the Research Institute of Petroleum Industry and the Department of Chemistry, University of Kharazmi, Tehran, Iran.

\section{References}

[1] Su, Y., Wei, H., Zhou, Z., Yang, Z., Wei, L. and Zhang, Y. (2011) Rapid Synthesis and Characterization of Magnesium oxide Nanocubes via DC Arc Discharge. Materials Letters, 65, 100-103. http://dx.doi.org/10.1016/j.matlet.2010.09.015

[2] Shen, G., Chen, P.C., Ryu, K. and Zhou, C. (2009) Devices and Chemical Sensing Applications of Metal Oxide Nanowires. Journal of Materials Chemistry, 19, 828-839. http://dx.doi.org/10.1039/B816543B

[3] Comini, E., Baratto, C., Faglia, G., Ferroni, M., Vomiero, A. and Sberveglieri, G. (2009) Quasi-One Dimensional Metal Oxide Semiconductors: Preparation, Characterization and Application as Chemical Sensors. Progress in Materials Science, 54, 1-67. http://dx.doi.org/10.1016/j.pmatsci.2008.06.003

[4] Takahashi, N. (2007) Simple and Rapid Synthesis of MgO with Nano-Cube Shape by Means of a Domestic Microwave Oven. Solid State Sciences, 9, 722-724. http://dx.doi.org/10.1016/j.solidstatesciences.2007.05.007

[5] Kato, Y., Takahashi, F., Watanabe, A. and Yoshizawa, Y. (2001) Thermal Analysis of a Magnesium Oxide/Water Chemical Heat Pump for Cogeneration. Applied Thermal Engineering, 21, 1067-1081.

[6] Klug, K.L. and Dravid, V.P. (2002) Observation of Two- and Three-Dimensional Magnesium Oxide Nanostructures 
Formed by Thermal Treatment of Magnesium Diboride Powder. Applied Physics Letters, 81, 1687-1689. http://dx.doi.org/10.1063/1.1502003

[7] Jüstel, T. and Nikol, H. (2000) Optimization of Luminescent Materials for Plasma Display Panels. Advanced Materials, 12, 527-530. http://dx.doi.org/10.1002/(SICI)1521-4095(200004)12:7<527::AID-ADMA527>3.0.CO;2-8

[8] Zheng, B., Lu, C., Gu, G., Makarovski, A., Finkelstein, G. and Liu, J. (2002) Efficient CVD Growth of Single-Walled Carbon Nanotubes on Surfaces Using Carbon Monoxide Precursor. Nano Letters, 2, 895-898. http://dx.doi.org/10.1021/nl025634d

[9] Wagner, G.W., Bartram, P.W., Koper, O. and Klabunde, K.J. (1999) Reactions of VX, GD, and HD with Nanosize MgO. The Journal of Physical Chemistry B, 103, 3225-3228. http://dx.doi.org/10.1021/jp984689u

[10] Hao, Y., Meng, G., Ye, C., Zhang, X. and Zhang, L. (2005) Kinetics-Driven Growth of Orthogonally Branched SingleCrystalline Magnesium Oxide Nanostructures. The Journal of Physical Chemistry B, 109, 11204-11208. http://dx.doi.org/10.1021/jp050545l

[11] Xu, B.Q., Wei, J.M., Wang, H.Y., Sun, K.Q. and Zhu, Q.M. (2001) Nano-MgO: Novel Preparation and Application as Support of Ni Catalyst for $\mathrm{CO}_{2}$ Reforming of Methane. Catalysis Today, 68, 217-225. http://dx.doi.org/10.1016/S0920-5861(01)00303-0

[12] Xie, Y. and Yuan, C. (2003) Visible-Light Responsive Cerium Ion Modified Titania Sol and Nanocrystallites for X-3B Dye Photodegradation. Applied Catalysis B: Environmental, 46, 251-259. http://dx.doi.org/10.1016/S0926-3373(03)00211-X

[13] Meshkani, F. and Rezaei, M. (2010) Effect of Process Parameters on the Synthesis of Nanocrystalline Magnesium Oxide with High Surface Area and Plate-Like Shape by Surfactant Assisted Precipitation Method. Powder Technology, 199, 144-148. http://dx.doi.org/10.1016/j.powtec.2009.12.014

[14] Natter, H., Schmelzer, M., Löffler, M.S., Krill, C.E., Fitch, A. and Hempelmann, R. (2000) Grain-Growth Kinetics of Nanocrystalline Iron Studied in Situ by Synchrotron Real-Time X-Ray Diffraction. The Journal of Physical Chemistry B, 104, 2467-2476. http://dx.doi.org/10.1021/jp991622d

[15] Zhang, J., Sun, L., Yin, J., Su, H., Liao, C. and Yan, C. (2002) Control of ZnO Morphology via a Simple Solution Route. Chemistry of Materials, 14, 4172-4177. http://dx.doi.org/10.1021/cm020077h

[16] Straumal, B.B., Protasova, S.G., Mazilkin, A.A., Baretzky, B., Myatiev, A.A., Straumal, P.B., et al. (2012) Amorphous Interlayers between Crystalline Grains in Ferromagnetic ZnO Films. Materials Letters, 71, 21-24. http://dx.doi.org/10.1016/j.matlet.2011.11.082

[17] Samodi, A., Rashidi, A., Marjani, K. and Ketabi, S. (2013) Effects of Surfactants, Solvents and Time on the Morphology of MgO Nanoparticles Prepared by the Wet Chemical Method. Materials Letters, 109, 269-275. http://dx.doi.org/10.1016/j.matlet.2013.07.085

[18] Jung, H.S., Lee, J.K., Kim, J.Y. and Hong, K.S. (2003) Crystallization Behaviors of Nanosized MgO Particles from Magnesium Alkoxides. Journal of Colloid and Interface Science, 259, 127-132. http://dx.doi.org/10.1016/S0021-9797(03)00034-1

[19] Chittofrati, A. and Matijević, E. (1990) Uniform Particles of Zinc Oxide of Different Morphologies. Colloids and Surfaces, 48, 65-78. http://dx.doi.org/10.1016/0166-6622(90)80219-T

[20] Kwon, Y.J., Kim, K.H., Lim, H.S. and Shim, K.B. (2002) J. of Ceram. Proc. Res, 3, 146-149. 